\title{
High-pressure chemical injection injury to the hand: usually underestimated injury with major consequences
}

\author{
Raman Sharma, ${ }^{\oplus}$ Jerry R John, Ramesh Kumar Sharma
}

Plastic Surgery, Post Graduate Institute of Medical Education and Research, Chandigarh, India

Correspondence to Dr Raman Sharma, dr.sharma.raman@gmail.com

Accepted 1 September 2019

\section{SUMMARY}

The damages caused by high-pressure injuries are often underestimated. Such incidents are characterised by a small punctiform entry wound and the normal colour of skin. The internal damage caused by these injuries can be severely devastating in nature. These injuries required emergent surgical debridement and irrigation. Postoperatively intensive physiotherapy is required for the successful return of hand function. The final functional outcome depends on the initial latency to treatment, nature of injected material, location and volume of injection and postoperative physiotherapy.

\section{BACKGROUND}

High-pressure injuries (HPIs) are very rare entities affecting the hands. These injuries are caused by the guns ejecting high-pressure jet streams emitting streams at pressure exceeding thousands of pounds force per square inch (psi). The incidence of these injuries is one in every 600 hand traumas. On an average, only one to four HPIs to hand are treated by even high-volume centres in an entire year. ${ }^{1}$

Paint, solvents, automotive grease and diesel oil include the most commonly injected materials in HPIs. This high pressure leads to diffusion of injected material into the tendon sheath, along neurovascular bundles and fascial planes. Thus closed and poorly distensible compartment-like

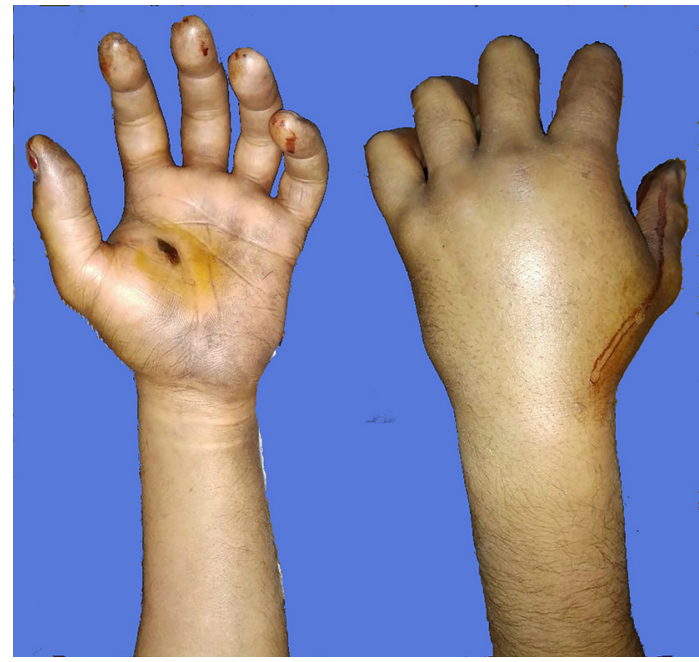

Figure 1 A small punctiform entry wound in the thenar aspect with no exit wound. digital and palmar tissues are badly affected. Overall deleterious effect is due to the raised pressure in the closed compartment, direct toxic effect of the chemical injected, mechanical impact of injury and secondary infections. ${ }^{2-4}$

These injuries are mostly underestimated because of small entry wound and initial benign look on inspection. Further, they occur accidentally during the leakage of pipes or during cleaning of the apparatus. The whole incident is over in a fraction of a second, that its severity is overlooked. ${ }^{45}$

This article reports a case of a high-pressure chemical injection Injury to the hand with extensive internal damage of soft tissue in comparison with the punctiform external wounds, its management and an early return of the hand function.

\section{CASE PRESENTATION}

A 42-year-old right-handed industrial worker was brought to the trauma centre 3 hours after sustaining an injury to his left hand from the high-pressure chemical jet that he was operating. The nozzle of the chemical pipe line accidentally opened and momentarily came into contact with the palm of left hand. The chemical that he was handling was ferric oxide. The pressure in the pipeline was around 4000 psi. There was minimal bleeding at the scene. On arrival in the trauma centre, he complained of severe pain and swelling in the hand, exacerbated by any active movement. He had one $1 \mathrm{~cm}$ entry wound marks on his left palm in the thenar region about $5 \mathrm{~cm}$ distal to the distal wrist crease. The entry wound and adjacent skin over the palm was very tender. There were no exit wounds visible. There was obvious swelling in the hand when compared with the opposite hand. Radial and ulnar pulses were palpable. The capillary refill time was delayed in the index and middle finger and normal in the rest of fingers. His vital signs were within normal limits. Sensory function of the hand was intact. Motor function was present, but he experienced severe hand and forearm pain on active and passive flexion and extension of left hand fingers and wrist. The range of finger movements was restricted (figure 1).

\section{INVESTIGATIONS}

Anteroposterior and lateral radiographs of the left forearm, elbow and hand confirmed the presence of subcutaneous emphysema extending from palmar region till midforearm. Radiopacity could be seen 

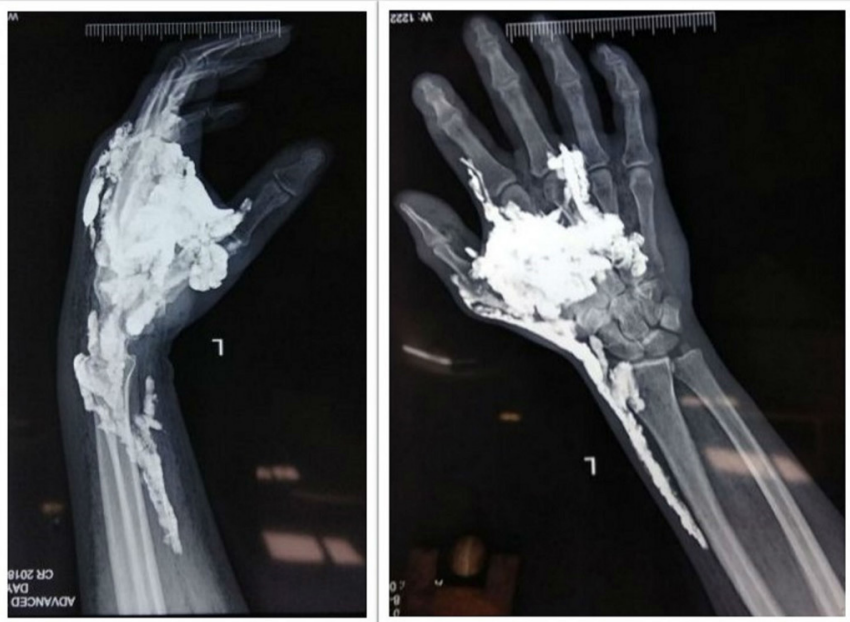

Figure 2 Anterior, posterior and lateral view of radiograph showing the presence of radio dense material in the palm and distal forearm.

in the mid palmar region extending till the distal flexor forearm compartment. No bony injuries were seen (figure 2).

\section{DIFFERENTIAL DIAGNOSIS}

The differential diagnosis in the acute setting includes a crush injury to the hand, compartment syndrome of the hand, fractures of the hand and digits or just a localised benign laceration of the digit or palm. If the patient presents late, several days after the initial injury, then one must also be suspicious for flexor tenosynovitis or an infections of the digits and hand.

\section{TREATMENT}

He was initially treated with intravenous augmentin (amoxicillin and clavulinic acid) $1.2 \mathrm{~g}$ intravenous and tetanus toxoid $0.5 \mathrm{~mL}$ intramuscularly. He had ongoing pain that was treated with analgesics. He underwent an emergency surgical exploration of left forearm and hand. First, the entry wound was extended proximally to the hand and forearm. A fasciotomy was performed in the dorsum of hand in the second and forth metacarpal spaces.

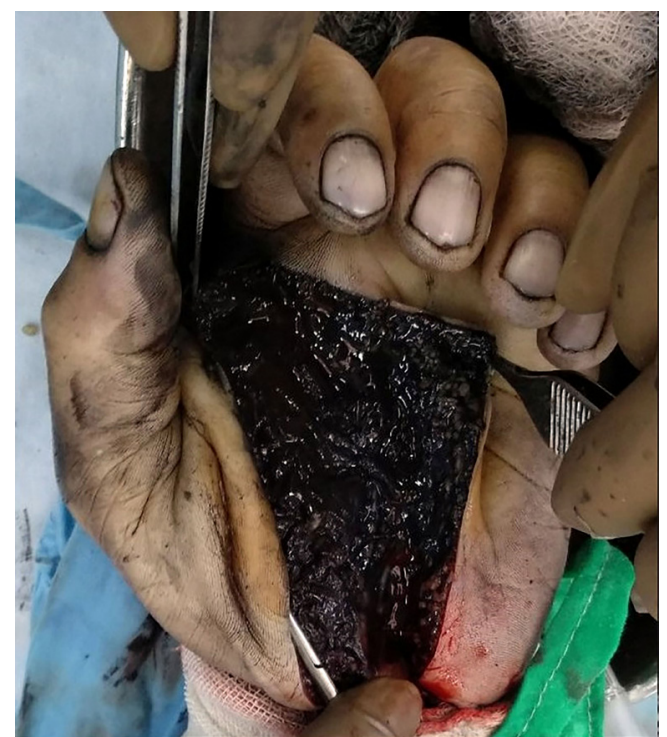

Figure 3 Debridement of necrotic tissue and the presence of chemical agent (ferric oxide) in the palm.

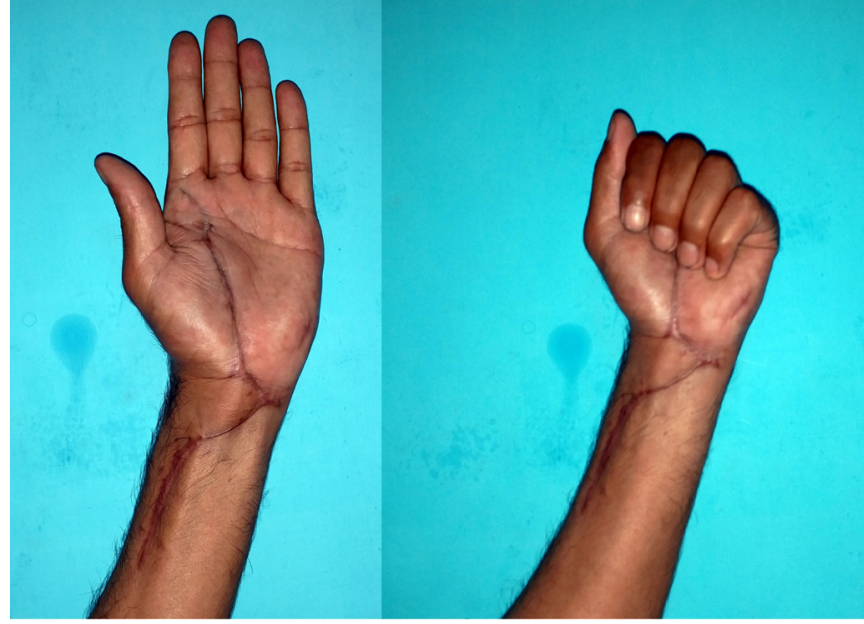

Figure 4 Normal motor and sensory function 4 months post operation.

The wound revealed a large amount of dark brown colour dye (ferric oxide) in the palm and distal flexor compartment. The material had penetrated and coated every distinguishable local anatomical structure. The anterior compartment muscles were soft. Neurovascular structures were identified and were intact. Thorough irrigation of the hand and anterior compartment with normal saline was performed and the wounds were left open and dressed (figure 3).

Postoperatively, he was treated with intravenous augmentin and adequate analgesia was given. After 2 days, a second debridement was performed. More of chemical could be removed and the stained tissues assessed for viability. Thorough irrigation was done. Again, after two more days, the wounds were explored. Further debridement of non-viable tissue followed by copious irrigation was done. Almost all of the contaminant chemical was now flushed out. The wounds were loosely approximated with interrupted non-absorbable sutures.

Postoperatively, splintage was provided to the upper extremity in the functional position. The patient was continued on intravenous augmentin for the next 24 hours. Adequate analgesia and elevation of the hand was ensured. Patient remained afebrile for 24 hours and was discharged home on oral augmentin and paracetamol for pain. After 10 days, all wounds healed. Supervised physiotherapy was started.

\section{OUTCOME AND FOLLOW-UP}

After 4 months on serial follow-ups, the surgical scar had healed well and he had normal motor and sensory functions of the left hand and forearm. He had recovered complete active and passive range of motion of fingers and wrist. He had a normal sensory function but the maximum grip strength had diminished slightly (figure 4).

\section{DISCUSSION}

Rees in the year 1937 first described the high-pressure jet injury with diesel fuel. In $60 \%$ of cases, the non-dominant hand is involved. Index finger is involved in nearly $50 \%$ of such injuries, followed by the thumb. In $10 \%$ of cases, the palm and other regions are involved. ${ }^{16}$

Paints, solvents, automotive grease and diesel oil include the most commonly injected materials. Diffusion of high kinetic energy in a closed anatomical compartment results in a devastating soft tissue and vascular injuries. If the operating 
Patient's perspective

It was just like another day of work for me but I never realised that a little mistake will put me into a massive trouble for next few months. While working with high-pressure chemical injecting device, in a fraction of second it came into contact with my left hand. After the incident, I had a look at my hand and I realised there was a small wound in my hand and minimal to no bleeding. I could feel the pain and the difficulty in the hand movement. It became difficult for me to continue with the work. At that point I contacted few of my colleagues. They advised me to visit the local practitioner for the first aid since it was just a punctiform wound. But pain was increasing in intensity. I rushed to the emergency and trauma centre. Their team of doctors examined me and quickly got the investigations done. They showed me the X-rays and informed me regarding the severity and seriousness of injury. I was shocked to see the amount of chemical which had entered through that trivial-looking wound. The doctors advised me for an emergency surgery in order to save my hand. I consulted my family and gave consent for the surgery. A team of doctors operated on my left upper limb. After the first surgery, they informed me how much of chemical was present and they tried their best to remove as much as chemical as possible. One day later, dressing was opened to assess the wound and doctors decided to go in for a surgery again to remove the dead tissues and chemicals which were remaining. After 48 hours, I was again in the operation theatre. This time doctors had removed almost all of the chemicals and dead tissues. After that they used to assess and dress the wound everyday for the next 5 days and later on alternate day for the next 10 days. There was a sigh of relief once all of my wounds were healed. The next big thing on my mind was to regain the functionality. My treating doctors in consultation with the physiotherapist put me on a strict physiotherapy protocol. Initially it was very painful, even at the slightest of the movement. But my doctors and physiotherapist motivated me and I followed the physiotherapy protocol religiously. I could see the movements of my hand returning and it improved as days passed by. After 4 months of physiotherapy, I was able to move my fingers and hand comfortably. I returned to my work and daily routine. It was a great relief for my wife and family members. The doctors and my family supported me really well to bring me to a normal life. I realised how important it is to follow the precautions while working with these kinds of instruments. A moment of carelessness can lead to a very severe physical and mental trauma. It's better to be safe than to feel sorry in the end.

temperature of the injected solvent is very high then it accentuates the injury by burning the underlying soft tissues and skin. These substances produce chemical irritation, acute and chronic inflammatory reactions with draining sinuses and fibrosis. Most devastating of all the chemicals is the paint solvent, which can result in amputation in $60 \%-80 \%$ of cases. ${ }^{45}$

Various mechanisms that are responsible for these injuries these includes:

1. Pressure-a pressure of 7 bar in enough for skin penetration. As the pressure increases, direct contact with skin is not required for infiltration into the subcutaneous tissues. The injected fluid preferentially follows the path of least resistance along the neurovascular bundle and fascial planes. The ultimate consequence is traumatic dissection of tissue, compression of neurovascular bundles, vascular spasm,
Learning points

- high-pressure injuries (HPIs) are rare industrial injuries, which if not addressed early and aggressively can lead to high degree of morbidity.

- Initial presentation of HPI can be very mystifying and can baffle the treating surgeon.

- Early, aggressive and serial debridements and fasciotomy should be done for their early management

- For an early return of function, an aggressive supervised physiotherapy protocol should be followed.

- There should be regular workshops and awareness campaign on the regular basis for the industrial workers on the proper handling of high-pressure injection devices while operating and in case of some event, a quick referral to the competent centre.

tissue ischaemia and oedema. A compartment syndrome may develop.

2. Chemical nature of substance-some chemicals have cytolytic properties which can result in intense inflammatory response, tissue destruction and necrosis. Consequently, a severe fibrosis may set in and can lead to impairment of hand function.

3. Infection-it can happen primarily during the HPI but secondary infections are more common which may be due to ischaemia and necrosis. ${ }^{1378}$

Initially, the patient may present with very minimal complaint, mostly with a small punctiform skin wound. Pain and swelling may develop after several hours. Sensory and motor impairment may be discovered later on. On an average, a patient seeks medical advice only after 9 hour of injury. The instantaneous nature of the event and Initial benign appearance of the injury may result in delays in seeking treatment. ${ }^{1}$

Radiological investigations are mandatory to know the extent of damage and involvement. Subcutaneous and soft tissue emphysema can be appreciated and its extent gives a good indication of the spread of the substance. Since there is involvement of fascial planes, the radiography must include proximal and distal regions for evaluating the extent of involvement. Imaging should be repeated after every surgical debridement.

If vascular compromise is suspected then urgent angiography should be performed for the evaluation of vascular injury site and extent. According to few authors, presence of distal pulse does not exclude an arterial injury and preoperative angiography should be performed. ${ }^{6}$

HPIs are surgical emergencies and patients need an immediate consultation and intervention. An early debridement must be performed in order to decrease the morbidity. Sooner the surgical intervention lowers the morbidity. Initial management include quick brief into history including the type of chemical, distance of jet from the skin surface and time of injury. High suspicious of extensive internal injury should be kept in the mind. Careful neurovascular examination followed by the radiological evaluation of site of injury and adjacent regions should be done. Tetanus prophylaxis, broad spectrum antibiotics and adequate analgesics should be given. Splinting and limb elevation should be done and urgent surgical decompression and debridement and copious irrigation should be done under adequate anaesthesia. Multiple episode of debridement and irrigation may be required over the time. Postoperatively aggressive physiotherapy should be done. 
The final hand function depends on various factors which include nature of injected substance, pressure at which it is injected, volume of injected substance and the site of injury. Solvent and paints have extensive cytolytic property. Moreover solvents have lower viscosity, and hence their spread and diffusion is very quick across tissue planes. Higher the pressure, more the volume of jet injected and therefore, more devastating the injury. The fingertip has smaller expansion capacity compared with the palm and hence a faster development of compartment syndrome. ${ }^{47910}$

Contributors This unusual case was diagnosed and managed by JRJ and RS. The article was researched and written by RS and JRJ and edited and supervised by RKS.

Funding The authors have not declared a specific grant for this research from any funding agency in the public, commercial or not-for-profit sectors.

Competing interests None declared.

Patient consent for publication Obtained.

Provenance and peer review Not commissioned; externally peer reviewed.

\section{REFERENCES}

1 Verhoeven N, Hierner R. High-pressure injection injury of the hand: an often underestimated trauma: case report with study of the literature. Strategies Trauma Limb Reconstr 2008;3:27-33.

2 Schoo MJ, Scott FA, Boswick JA. High-pressure injection injuries of the hand. J Trauma 1980;20:229-38.

3 Lewis HG, Clarke P, Kneafsey B, et al. A 10-year review of high-pressure injection injuries to the hand. J Hand Surg Br 1998;23:479-81.

4 Hogan CJ, Ruland RT. High-pressure injection injuries to the upper extremity: a review of the literature. J Orthop Trauma 2006;20:503-11.

5 Gonzalez R, Kasdan ML. High pressure injection injuries of the hand. Clin Occup Environ Med 2006;5:407-11.

6 Subramaniam RM, Clearwater GM. High-pressure water injection injury: emergency presentation and management. Emerg Med 2002;14:324-7.

7 Wieder A, Lapid O, Plakht Y, et al. Long-term follow-up of high-pressure injection injuries to the hand. Plast Reconstr Surg 2006;117:186-9.

8 Valentino M, Rapisarda V, Fenga C. Hand injuries due to high-pressure injection devices for painting in shipyards: circumstances, management, and outcome in twelve patients. Am J Ind Med 2003;43:539-42.

9 Hart RG, Smith GD, Haq A. Prevention of high-pressure injection injuries to the hand. Am J Emerg Med 2006;24:73-6.

10 Schnall SB, Mirzayan R. High-pressure injection injuries to the hand. Hand Clin 1999;15:245-8.

Copyright 2019 BMJ Publishing Group. All rights reserved. For permission to reuse any of this content visit https://www.bmj.com/company/products-services/rights-and-licensing/permissions/

BMJ Case Report Fellows may re-use this article for personal use and teaching without any further permission.

Become a Fellow of BMJ Case Reports today and you can:

- Submit as many cases as you like

- Enjoy fast sympathetic peer review and rapid publication of accepted articles

- Access all the published articles

Re-use any of the published material for personal use and teaching without further permission

\section{Customer Service}

If you have any further queries about your subscription, please contact our customer services team on +44 (0) 2071111105 or via email at support@bmj.com.

Visit casereports.bmj.com for more articles like this and to become a Fellow 